\title{
Performance of Hybrid Adhesives of Blocked-pMDI/Melamine-Urea-Formaldehyde Resins for the Surface Lamination on Plywood ${ }^{1}$
}

\author{
Muhammad Adly Rahandi Lubis ${ }^{2} \cdot$ Byung-Dae Park $\mathbb{D}^{2, \dagger} \cdot$ Sang-Min Lee $\mathbb{D}^{3, \dagger}$
}

\begin{abstract}
To improve the water resistance of melamine-urea-formaldehyde (MUF) resins, different levels of blocked polymeric 4,4 diphenyl methane diisocyanate (B-pMDI) were blended with MUF resins to prepare B-pMDI/MUF hybrid adhesives, and their adhesion performances were evaluated for the surface lamination of fancy veneer on plywood. FT-IR spectra showed that the de-blocked - NCO groups reacted with the - $\mathrm{OH}$ of hydroxymethyl groups of the MUF resins to form urethane bonds at 2\% B-pMDI/MUF, which was detected before and after their hydrolysis. The mass loss after the hydrolysis consistently decreased as the B-pMDI level increased, indicating an improvement in the water resistance. As the B-pMDI level increased, the activation energy of hybrid adhesives decreased, which improved the reactivity of the hybrid adhesives. Additionally, the water resistance improvement of the hybrid adhesives increased the tensile shear strength of the surface laminated plywood in semi-water proof and water-proof by $23 \%$ and $8 \%$, respectively, at $2 \%$ B-pMDI level. This was likely due to the urethane linkages in the hybrid adhesives. However, the formaldehyde emission from plywood panels bonded with the hybrid adhesives increased in the dry state, indicating incomplete curing of the hybrid adhesives.
\end{abstract}

Keywords: blocked pMDI, MUF resins, plywood, surface lamination, water resistance

\section{INTRODUCTION}

Urea-formaldehyde (UF) resins, phenol-formaldehyde (PF) resins, melamine-formaldehyde (MF) resins, and melamine-urea-formaldehyde (MUF) resins are classified as poly-condensation resins which are commonly used in wood industry (Dunky, 2004; Merline et al., 2013). Owing to greater adhesion strength than UF resins and less expensive than MF resins (Pizzi, 2003),
MUF resins have been widely used for the production of exterior grade wood-based panels (Tohmura et al., 2001; Zhou et al., 2012). Superior properties of MUF-bonded panels are obtained due to the presence of two reactive monomers in MUF resins, namely urea and melamine, which are ready for the reaction with formaldehyde (Siimer et al., 2008). In particular, the production of plywood panel still relies on inexpensive UF resins adhesive (Dunky, 1998). However, due to

\footnotetext{
${ }^{1}$ Date Received January 17, 2019, Date Accepted March 4, 2019

2 Department of Wood and Paper Sciences, Kyungpook National University, Daegu, Republic of Korea

${ }^{3}$ Department of Forest Products, National Institute of Forest Science, Seoul, Republic of Korea

$\dagger$ Corresponding author: Byung-Dae Park (e-mail: byungdae@knu.ac.kr, ORCID: 0000-0002-9802-7855)

$\dagger$ Corresponding author: Sang-Min Lee (e-mail: sml5@korea.kr, ORCID: 0000-0002-9089-5260)
} 
its relatively poor dimensional stability which results in warping and cracking, MUF resins then becomes a viable option (Stöckel et al., 2010).

One of the use of plywood is for lamination on engineering flooring. The laminate flooring usually consists of high density fiberboard or plywood with a thin fancy veneer (Kim and Kim, 2005; Kim, 2009). And types of the surface lamination materials also influenced the formaldehyde emission from various woodbased composite panels (Park et al., 2016). However, the use of MUF resins as adhesive can lead to delamination and bond deterioration due to its low hot water resistance (Jiang and Lu, 2017). This is because of the water molecules first attacks the hydroxymethyl $\left(-\mathrm{CH}_{2} \mathrm{OH}\right)$ end groups (Lubis and Park, 2018), and then splits the methylene (-NH- $\left.\mathrm{CH}_{2}-\mathrm{NH}-\right)$ linkages of MUF resins (Pizzi, 2003; Park et al., 2009). To overcome this, organic and inorganic fillers have been added into MUF resins, however, it partly retarded the curing of MUF resins (Mamiński et al., 2007; Cai et al., 2010; Li et al., 2016). In addition, the synthesis method and molecular weight of MUF resins had a great impact to the performance of wood fiberboard (Jeong and Park, 2016). A new modification of MUF resins was done by mixing with $10 \%$ of liquid polyurethane pre-polymer, which improved the wet adhesion strength of plywood (Jiang and Lu, 2017). However, the pre-polymer resins, polymeric 4-4 diphenyl methane diisocyanate (pMDI), still have high content of reactive -NCO groups, which makes the direct application of polyurethane pre-polymer difficult. A way to overcome this is by preparing blocked pMDI resins, which needs specific temperature to release the masked -NCO groups (Wicks and Wicks, 2001; Delebecq et al., 2013).

A blocked isocyanate (B-pMDI) is produced via a reaction between an -NCO group and a compound containing an active hydrogen atom. This product has the advantage of a long shelf life because the active isocyanate groups are masked and protected (Wicks and Wicks, 1999). B-pMDI/PF and B-pMDI/UF resins adhesives has been recently used to produce woodbased panels with greater performance than that of bonded with the neat resins (Gopal et al., 2014; Lubis et al., 2017). However, the use of B-pMDI on improving the performance of MUF resins, particularly on surface lamination of plywood, has not been reported elsewhere. Therefore, the objective of this study is to prepare hybrid adhesives based on the blending of different levels of B-pMDI into MUF resins (B-pMDI/MUF). Further, the paper aims to investigate the chemistry and thermal properties of hybrid adhesives, and to evaluate the surface laminate properties of plywood bonded with B-pMDI/MUF hybrid adhesives.

\section{MATERIALS and METHODS}

\subsection{Materials}

A commercial MUF resin (M-60N, Donghwa Taeyang Chemical, Incheon, Korea) was used for the lamination of $2 \mathrm{~mm}$ thick fancy veneers from Sugar Maple (Acer saccharum) on the surface of 5-ply plywood panel (7.5 mm thickness) from Meranti veneers (Shorea spp.). 3\% $\mathrm{NH}_{4} \mathrm{Cl}$ (20 wt\% solution) was used as a catalyst. Liquid pMDI (Lupranate M20S, BASF, Germany) with $31 \%$-NCO content, sodium bisulphite $\left(\mathrm{NaHSO}_{3}, 58.5 \mathrm{wt} \%\right)$, and acetone (99.8 wt\%) were used to prepare the blocked pMDI (B-pMDI).

\subsection{Preparation of $\mathrm{B}-\mathrm{pMDI} / \mathrm{MUF}$ hybrid adhesives}

B-pMDI resins with a $\mathrm{HSO}_{3} / \mathrm{NCO}$ mole ratio of 1.5:1 and de-blocking temperature of $78.3^{\circ} \mathrm{C}$ was prepared according to a published method (Lubis et al., 2017). Commercial MUF resins were mixed with three levels of B-pMDI (0, 1, and $2 \mathrm{wt} \%)$ based on the non-volatile solids content of MUF resins. 


\subsection{Fancy veneer lamination on the plywood surface}

Fancy veneers were glued on the surface lamination of 5-ply plywood by adding $3 \% \mathrm{NH}_{4} \mathrm{Cl}$ into the B-pMDI/MUF hybrid adhesives at three levels of B-pMDI. The glue spread was $135 \mathrm{~g} / \mathrm{m}^{2}$ for neat MUF resins and $170 \mathrm{~g} / \mathrm{m}^{2}$ was used for $1 \%$ and $2 \%$ B-pMDI/MUF because of their high viscosity for 1 and 2\% B-pMDI levels. The surface lamination of fancy veneers on plywood was done by hot-pressing for 5 $\min$ at $120^{\circ} \mathrm{C}$ and $10 \mathrm{kgf} / \mathrm{cm}^{2}$ of pressure. The samples were conditioned for $24 \mathrm{~h}$ prior to cutting and testing. The moisture content of plywood panel was ranged from $7.1 \%$ to $7.4 \%$.

\subsection{Characterization of $\mathrm{B}-\mathrm{pMDI} / \mathrm{MUF}$ hybrid adhesives}

The properties of B-pMDI/MUF hybrid adhesives were determined according to the standard methods. The non-volatile solids content of the hybrid adhesives was obtained by drying $2 \mathrm{~g}$ of the sample in an oven at $105^{\circ} \mathrm{C}$ for $3 \mathrm{~h}$ and dividing the oven-dried weight by the initial weight. The viscosity of hybrid adhesives was determined using a cone-plate viscometer (DV-II+, Brookfield, USA) with the spindle No. 2 at 60 RPM and $27 \pm 2{ }^{\circ} \mathrm{C}$. The gelation time of the hybrid adhesives was measured by adding $3 \% \mathrm{NH}_{4} \mathrm{Cl}$ and different levels of B-pMDI based on the non-volatile solids content of the MUF resins. The measurements were performed in boiling water using a gelation time meter (Davis Inotek Instrument, Charlotte, USA). The $\mathrm{pH}$ value of hybrid adhesives was measured using a digital pH meter. Each experiment was repeated three times.

A differential scanning calorimetry (DSC, Discovery 25, TA Instruments, USA) was used to investigate the exothermic peak temperature (Tp) and activation energy $\left(E_{a}\right)$ of the B-pMDI/MUF hybrid adhesives at different levels of B-pMDI. Approximately $5 \mathrm{mg}$ of the adhesives mixed with $3 \% \mathrm{NH}_{4} \mathrm{Cl}$ was sealed in a high-pressure capsule pan and then heated from 30 to $200^{\circ} \mathrm{C}$ at different heating rates of $2.5,5,10$, and $20^{\circ} \mathrm{C} / \mathrm{min}$ under a nitrogen flow of $50 \mathrm{~mL} / \mathrm{min}$. The reactivity of B-pMDI/MUF hybrid adhesives was predicted by calculating their $E_{a}$ using the Kissinger method as described in the following equation (Kissinger, 1957):

$-\ln \left(\beta / T p^{2}\right)=-\ln \left(A R / E_{a}\right)+\left(1 / T_{p}\right)\left(E_{a} / R\right)$

where $\beta$ is the heating rate, $\mathrm{R}$ is the gas constant, $T p$ is the peak temperature, and $A$ is the pre-exponential factor. $E_{a}$ value can be obtained by plotting $-\ln \left(\beta / T p^{2}\right)$ versus $1 / T_{p}$.

Further, an attenuated total reflection of Fouriertransform infrared (ATR-FTIR) spectroscopy (Alpha P, Bruker Alpha, Germany) was performed to qualitatively investigate the functional groups of the cured B-pMDI/ MUF hybrid adhesives. The powder of cured hybrid adhesives were scanned from 400 to $4000 \mathrm{~cm}^{-1}$ with a resolution of $4 \mathrm{~cm}^{-1}$ and 32 scans per sample. Moreover, the cured B-pMDI/MUF hybrid adhesives were submitted to hydrolysis as a part of the evaluation of water resistance. Hydrolysis of the hybrid adhesives was done according to the published works (Park et al., 2009; Lubis and Park, 2018). Briefly, hydrolysis was accomplished by mixing $2 \mathrm{~g}$ of the powder adhesives and $200 \mathrm{ml}$ of distilled water in a $250 \mathrm{~mL}$ glass beaker at $80^{\circ} \mathrm{C}$ for $30 \mathrm{~min}$. The solid residues were obtained by filtration and drying. The solid residues then were analysed by ATR-FTIR spectroscopy to evaluate the change in functional groups after hydrolysis.

\subsection{Evaluation of properties of surface laminate plywood}

Tensile shear strength (TSS), delamination, and formaldehyde emission (FE) of surface lamination on 5-ply 
Table 1. Basic properties of B-pMDI/MUF hybrid adhesives as a function of B-pMDI content

\begin{tabular}{ccccc}
\hline B-pMDI content (wt\%) & $\mathrm{pH}$ & Non-volatile solids content (\%) & Viscosity (mPa.s) & Gelation time (s) \\
\hline \hline 0 & 8.2 & $56.9 \pm 0.15$ & $147 \pm 5.03$ & $127 \pm 3.21$ \\
1 & 8.2 & $57.8 \pm 0.17$ & $156 \pm 2.31$ & $123 \pm 3.05$ \\
2 & 8.2 & $58.6 \pm 0.42$ & $162 \pm 3.00$ & $121 \pm 5.56$ \\
\hline
\end{tabular}

plywood were tested according to Korean Standard (KS 2016). Around 10 samples were prepared the TSS (25 $\mathrm{mm} \times 80 \mathrm{~mm} \times 7.5 \mathrm{~mm})$, delamination $(75 \mathrm{~mm} \times 75 \mathrm{~mm}$ $\times 7.5 \mathrm{~mm})$ and FE $(150 \mathrm{~mm} \times 50 \mathrm{~mm} \times 7.5 \mathrm{~mm})$ measurements. Dry TSS was directly evaluated using a universal testing machine (UTM H50KS, Hounsfield, England) at heading speeds of $2 \mathrm{~mm} / \mathrm{min}$. For semi- water proof and water proof TSS, the samples were immersed in water at $60 \pm 3^{\circ} \mathrm{C}$ for $3 \mathrm{~h}$ and at $100 \pm 3^{\circ} \mathrm{C}$ for $4 \mathrm{~h}$, respectively. Semi-water proof and water proof TSS values were also evaluated using UTM. The FE values were measured using a 24-h desiccator method and UVvisible spectrophotometry (Optizen 3220 UV, Mecasys, Korea) at a wavelength of $412 \mathrm{~nm}$. Moisture content of surface laminate plywood was also measured according to the standard procedure. Briefly, samples were put in an oven at $105 \pm 2^{\circ} \mathrm{C}$ and were weighed and checked for every $1 \mathrm{~h}$ until reaching the constant weight.

\section{RESULTS and DISCUSSION}

\subsection{Effects of B-pMDI content on properties of MUF resins}

Basic properties of B-pMDI/MUF hybrid adhesives are presented in Table 1. Addition of B-pMDI altered the properties of commercial neat MUF resins, except $\mathrm{pH}$ value. Further, addition of 2\% B-pMDI into MUF resins increased non-volatile solids content and viscosity of the resins by $3 \%$ and $10 \%$, respectively. Meanwhile, gelation time was reduced up to $5 \%$ by adding $2 \%$ B-pMDI into MUF resins. This implies that B-pMDI improves the properties and reactivity of MUF resins. As depicted in Fig. 1b, after de-blocking, the free NCO groups of B-pMDI could react with $\mathrm{OH}$ of hydroxymethyl end group of MUF resins, and formed urethane linkage in the hybrid adhesives. Similar finding was found in pMDI/UF resins (Despres et al., 2006).
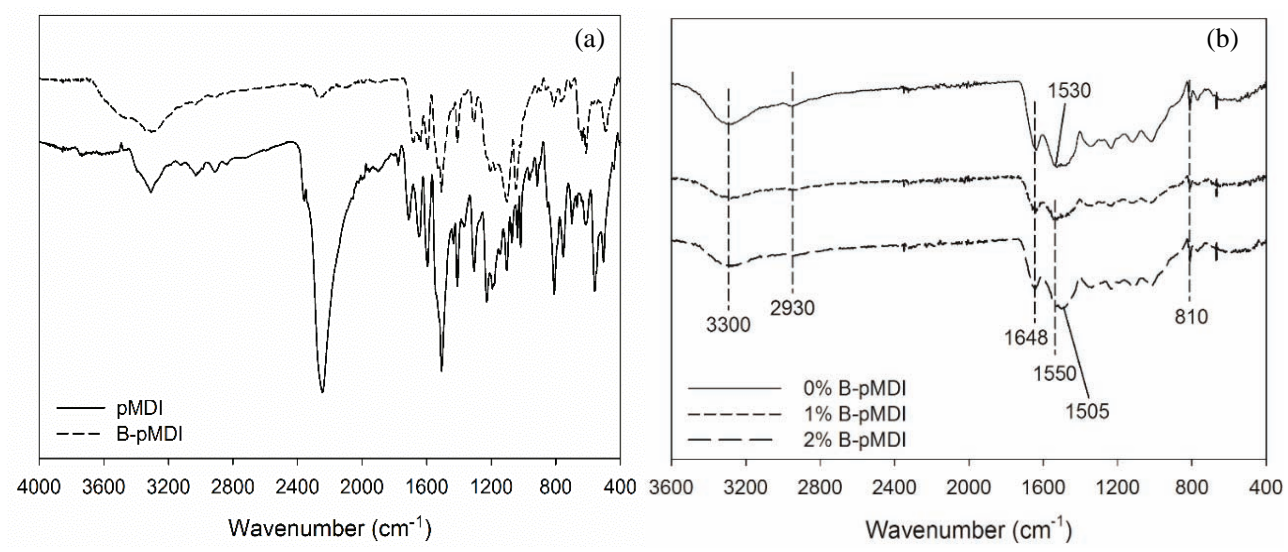

Fig. 1. ATR-FTIR spectra of B-pMDI (a), and cured B-pMDI/MUF adhesives with different contents of B-pMDI (b). 

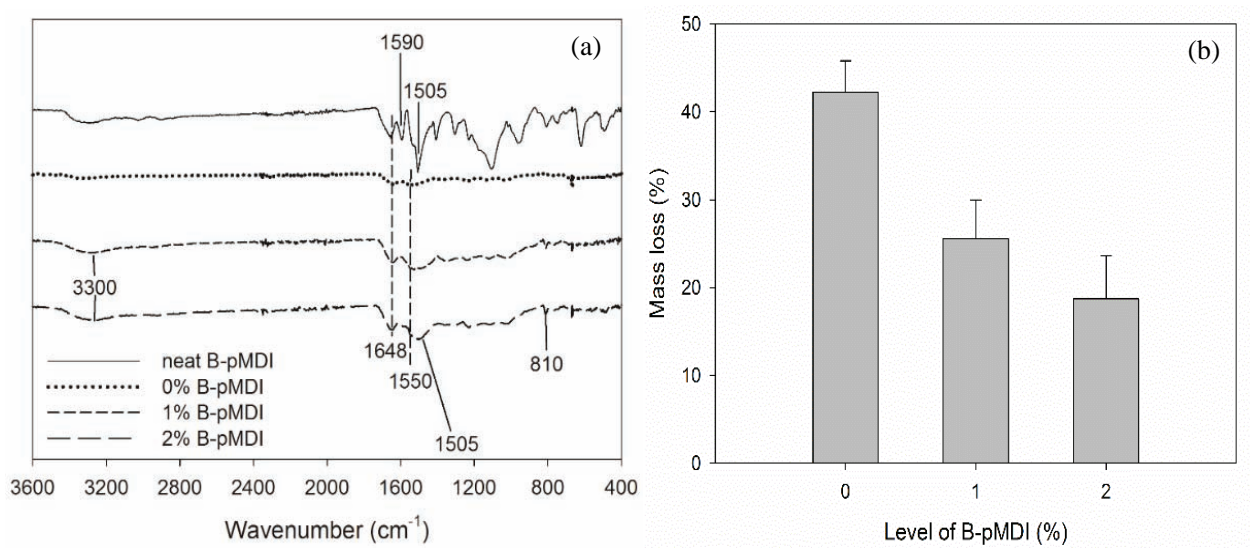

Fig. 2. Typical ATR-FTIR spectra of B-pMDI/MUF resins at different levels of B-pMDI after hydrolysis (a), and their mass loss (b).

Functional groups of B-pMDI and B-pMDI/MUF hybrid adhesives are displayed in Fig. 1. As expected, NCO group of pMDI at $2250 \mathrm{~cm}^{-1}$ was de-blocked after blocking reaction, while strong NCO peak was still detected in crude pMDI. Mixing different levels of B-pMDI in MUF resins did not alter the functional groups of MUF. Peak at $3300 \mathrm{~cm}^{-1}, 2930 \mathrm{~cm}^{-1}, 1648$ $\mathrm{cm}^{-1}, 1550 \mathrm{~cm}^{-1}$, and $810 \mathrm{~cm}^{-1}$ were assigned to $\mathrm{N}-\mathrm{H}$ stretch of amide, $\mathrm{C}-\mathrm{H}$ of mehtlyne linkage, $\mathrm{C}=\mathrm{O}$ of amide, $\mathrm{N}-\mathrm{H}$ bending of amide, and C-H of hydroxymehtyl end groups, respectively (Kandelbauer et al., 2007). Those peaks were observed in all hybrid adhesives. However, new peak of C-H of urethane appeared at $1505 \mathrm{~cm}^{-1}$ for $2 \%$ B-pMDI/MUF resins, indicating that higher content of B-pMDI could form urethane bond in B-pMDI/MUF hybrid adhesives. It should be noted that the presence of $\mathrm{C}=\mathrm{O}$ of urethane bond was probably overlapping with $\mathrm{C}=\mathrm{O}$ of primary amide.

To evaluate their hydrolytic stability, functional groups of B-pMDI/MUF hybrid adhesives after hydrolysis were also investigated. As displayed in Fig. 2a, it was possible that de-blocked -NCO groups of neat B-pMDI could react with -OH groups of water to form carbamic acid and further reaction could form biuret at $1590 \mathrm{~cm}^{-1}$ (Frihart 2005). Moreover, the presence of $\mathrm{C}-\mathrm{H}$ of urethane at $1505 \mathrm{~cm}^{-1}$ confirmed the formation of urethane bond in 2\% B-pMDI/MUF hybrid adhesives after hydrolysis.

In comparison to neat MUF resins, many peaks of MUF resins have disappeared after hydrolysis, except the main peak of $\mathrm{C}=\mathrm{O}$ and $\mathrm{N}-\mathrm{H}$ of primary amide at $1648 \mathrm{~cm}^{-1}$ and $1550 \mathrm{~cm}^{-1}$, respectively. The peak of $\mathrm{C}-\mathrm{H}$ of hydroxymethyl end groups at $810 \mathrm{~cm}^{-1}$ has completely vanished after hydrolysis, showing that hydrolysis readily attacked the hydroxymethyl end groups of the resins (Lubis and Park, 2018). However, after hydroxymethyl group reacted with NCO of B-pMDI to form urethane bond, the peak at $810 \mathrm{~cm}^{-1}$ was still detected in B-pMDI/MUF hybrid adhesives. The mass loss after their hydrolysis consistently decreased as the B-pMDI level increased, indicating an improvement of water resistance (Fig. 2b). Addition of 2\% B-pMDI into MUF resins improve the hydrolytic stability of hybrid adhesives by $52.7 \%$. This indicates that the presence of B-pMDI improves the water resistance and hydrolytic stability of hybrid adhesives by forming urethane bond.

Thermal properties of B-pMDI/MUF hybrid adhesives at different levels of B-pMDI are provided in Fig. 3. The $T p$ values of B-pMDI/MUF increased as a function of heating rate and the values decrease as level 

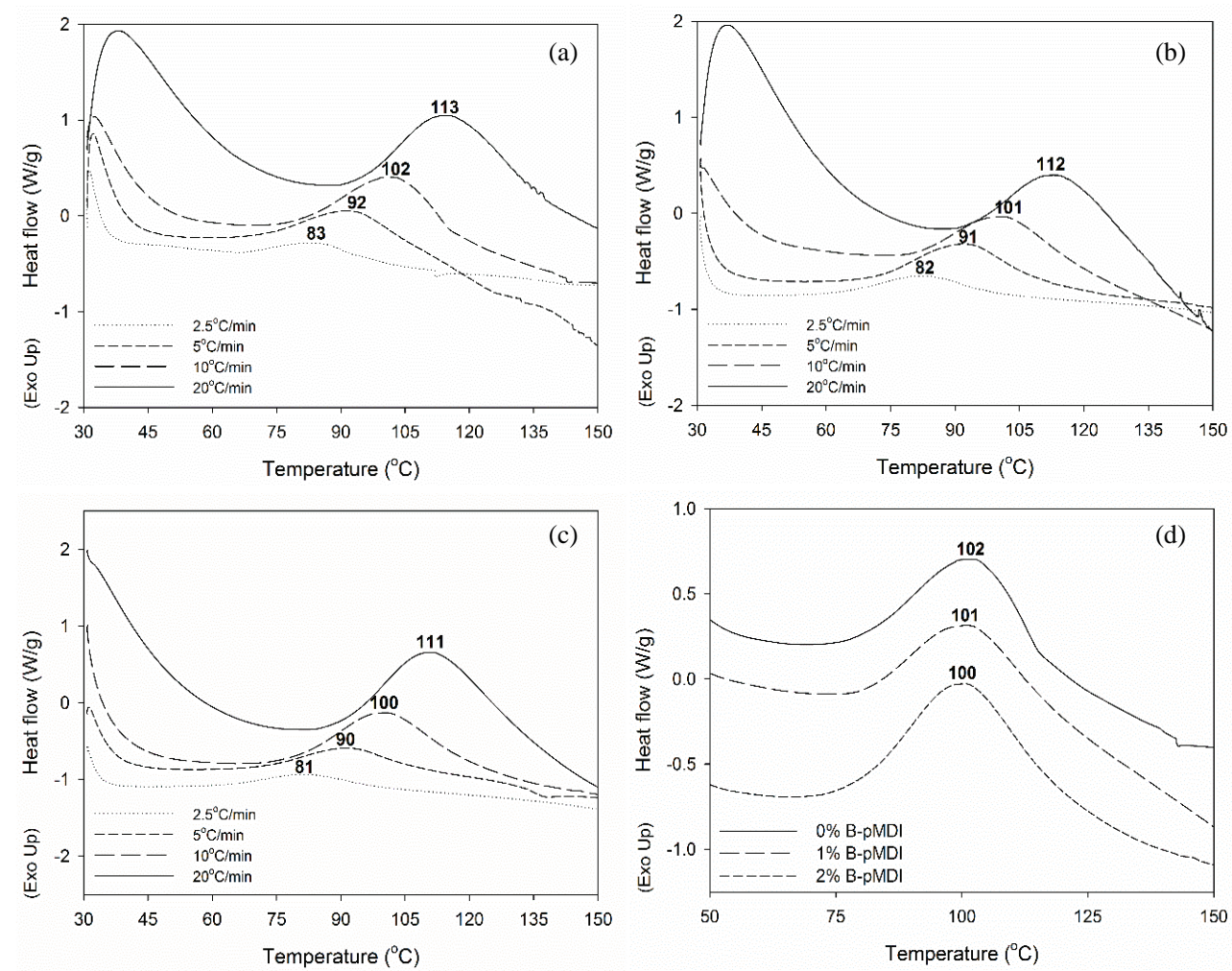

Fig. 3. DSC thermograms of B-pMDI/MUF resins at different contents of B-pMDI and different heating rates: neat MUF resins (a), 1\% B-pMDI/MUF adhesives (b), 2\% B-pMDI/MUF adhesives (c), typical DSC thermograms of B-pMDI/MUF adhesives at $10^{\circ} \mathrm{C} / \mathrm{min}$ (d).

of B-pMDI increased. Further, as can be seen in Fig. 3d, $T p$ value of hybrid adhesives only decreased by $2 \%$ with addition of $2 \%$ B-pMDI into MUF resins. This indicates that there is no clear influence of B-pMDI content on the $T p$ of B-pMDI/MUF hybrid adhesives. Same result was also found in B-pMDI/UF resins (Lubis et al., 2017).

Furthermore, $E_{a}$ values of B-pMDI/MUF hybrid adhesives were obtained by plotting the $T p$ values and heating rate into equation 1 (Fig. 4). $E_{a}$ values of hybrid adhesives decreased as the level of B-pMDI increased. This indicates that the reactivity of B-pMDI/MUF hybrid adhesives increased as a funtion of B-pMDI content. This finding was supported by the results of non-volatile solids content, vicosity, gelation time
(Table 1). Higher solids content and viscosity of hybrid adhesives were obtained at higher B-pMDI content, leading to a shorter gelation time. Thus, higher level of B-pMDI could reduce the $E_{a}$ values of B-pMDI/MUF hybrid adhesives. However, as showing by the same $\mathrm{R}^{2}$ values of the Kissinger plots, no significant reduction of $E_{a}$ values of B-pMDI/MUF was noted as a function of B-pMDI level. This was probably due to that not all de-blocked -NCO groups have reacted with $\mathrm{OH}$ of hydroxymethyl end groups of MUF resins.

\subsection{Performance of the surface lamination on plywood}

Tensile shear strength (TSS) values of surface lami- 

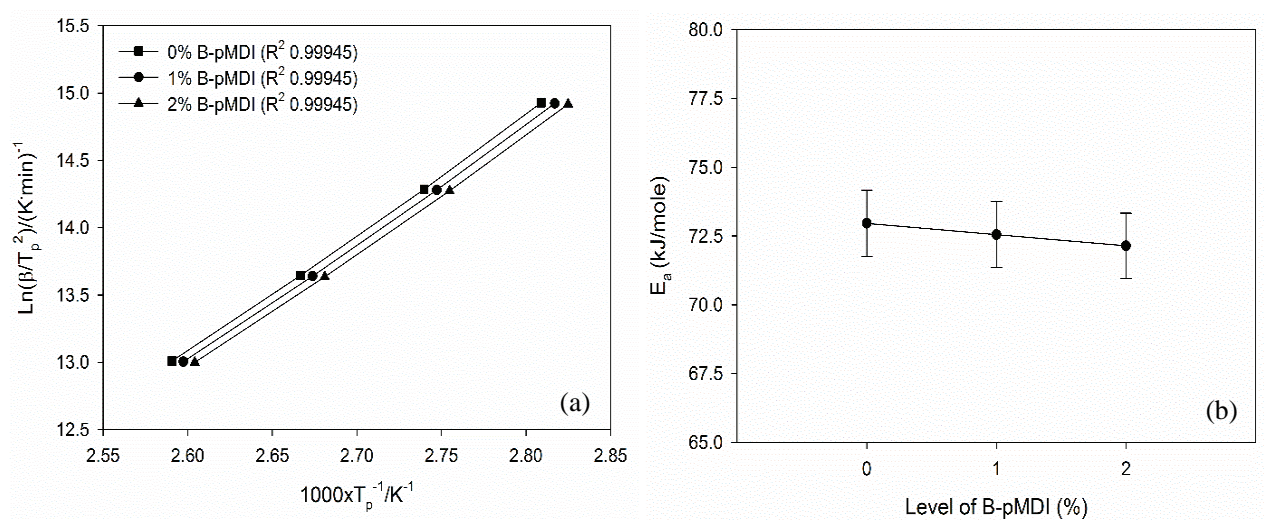

Fig. 4. Kissinger plot and $E a$ values of B-pMDI/MUF resins as a function of B-pMDI level.
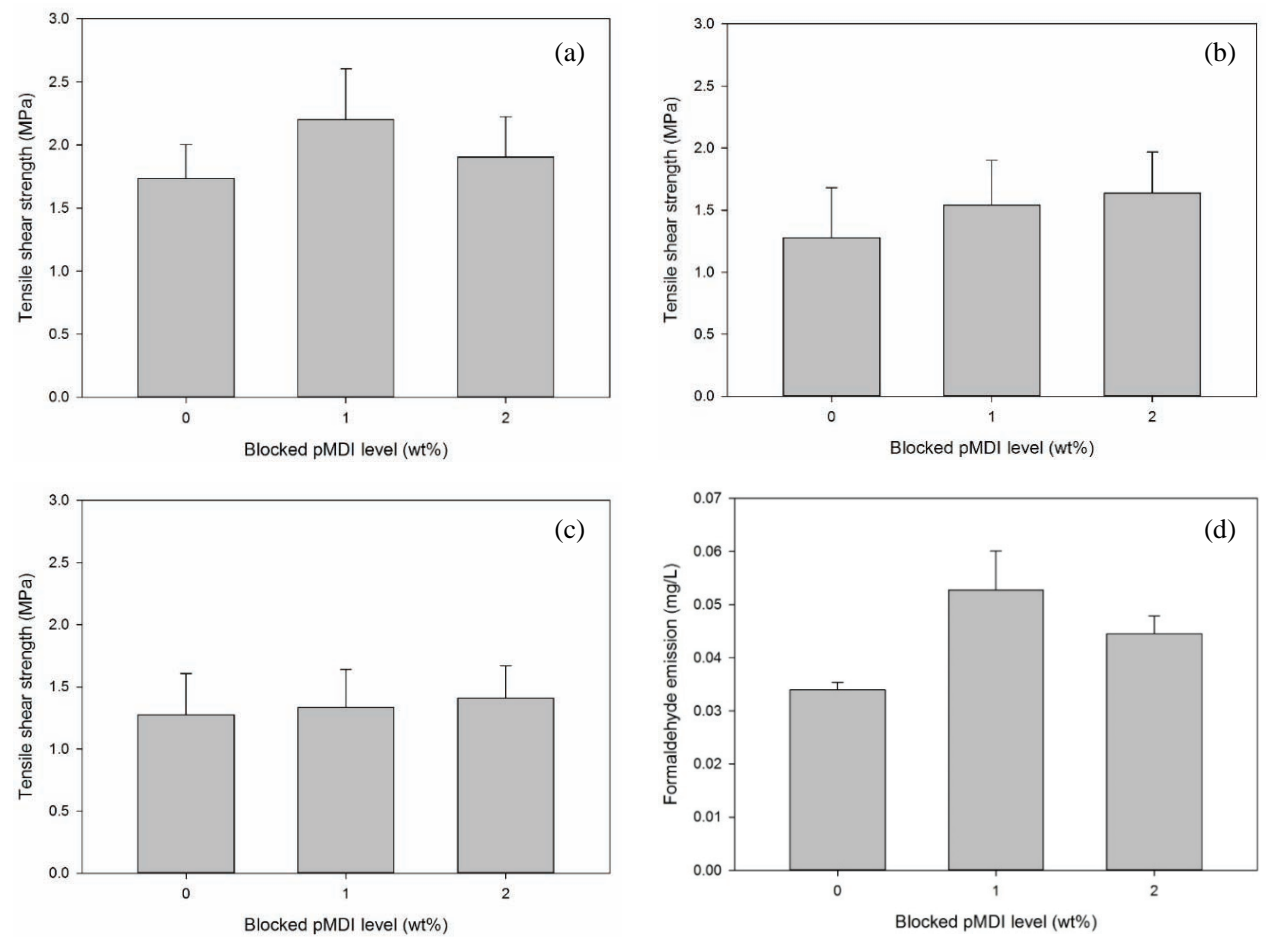

Fig. 5. TSS and formaldehyde emission (FE) of surface laminate plywood bonded with B-pMDI/MUF resins as a function level of B-pMDI: Dry TSS (a), semi water proof TSS (b), water proof TSS (c), and FE values (d).

nate plywood as a function of B-pMDI level are provided in Fig. 5. Dry TSS of surface laminate plywood increased by $28.5 \%$ with addition of $1 \%$ B-pMDI into MUF resins. However, TSS value of surface laminate plywood bonded with 2\% B-pMDI/MUF hybrid adhesives decreased to $1.85 \mathrm{MPa}$. But, it should be noted that addition of B-pMDI into MUF increased the TSS of surface laminate plywood than that of bonded with 
neat MUF resins. This could be due to the presence of urethane bond in B-pMDI/MUF hybrid adhesives (Jiang and Lu, 2017), which was also displayed in Fig. 1b. No significant result was observed in delamination of surface laminate plywood on dry state.

The water resistance of B-pMDI/MUF-bonded surface laminate plywood was evaluated as semi-water proof and water proof TSS (Fig. 5b and c). The results showed that both semi-water proof and water proof TSS values of surface laminate plywood increased as a function of B-pMDI level. It was noted that semi-water proof TSS increased up to $23.1 \%$ by adding $2 \%$ B-pMDI into MUF resins, while only $7.7 \%$ increment was observed in water-proof TSS with the same level of B-pMDI. This indicates that the presence of B-pMDI improves the water resistance of MUF resins by forming urethane bond. Similar finding was also found in pMDI/UF resins network (Simon et al., 2002; Mansouri et al., 2006). In addition, as depicted in Fig. 2a, de-blocked -NCO groups of B-pMDI could react with $\mathrm{OH}$ groups of water to form biuret at $1590 \mathrm{~cm}^{-1}$ (Frihart 2005). Moreover, the presence of $\mathrm{C}-\mathrm{H}$ of urethane at $1505 \mathrm{~cm}^{-1}$ confirmed the formation of urethane bond in 2\% B-pMDI/MUF hybrid adhesives after hydrolysis. This supported the results of semi-water proof and water proof of surface laminate plywood which increased at higher level of B-pMDI in MUF resins.

Formaldehyde emission (FE) values of surface laminate plywood are presented in Fig. 5d. FE of plywood panels bonded with the hybrid adhesives increased at dry condition. This could be attributed to either higher glue spread level or incomplete curing of the hybrid adhesives. As mentioned in DSC results (Fig. 4), reduction of $E_{a}$ values of B-pMDI/MUF was not significant. This could be due to that de-blocked -NCO groups have not reacted with $\mathrm{OH}$ of hydroxymethyl end groups of MUF resins. Therefore, no direct relation of level of B-pMDI on the reduction of FE from surface laminate plywood was observed.

\section{CONCLUSION}

In this study, different levels of blocked-polymeric 4-4 diphenyl methane diisocyanate (B-pMDI) were blended with MUF resins to prepare B-pMDI/MUF hybrid adhesives as a way of improving water resistance of MUF resins. And their adhesion performance was evaluated for the surface lamination of fancy veneer on plywood. The following conclusions were obtained:

1. FTIR spectra showed that the de-blocked -NCO groups reacted with the $-\mathrm{OH}$ of hydroxymethyl groups of MUF resins to form urethane bonds at 2\% B-pMDI/ MUF. The mass loss after their hydrolysis consistently decreased as the B-pMDI level increased, indicating an improvement of water resistance.

2. As the B-pMDI level increased, the activation energy of hybrid adhesives decreased, and led to an improved reactivity of the hybrid adhesives.

3. The water resistance improvement of hybrid adhesives was also supported by $23 \%$ and $8 \%$ increase in the tensile shear strength of the surface laminated plywood in semi-water proof and water, respectively, at $2 \%$ B-pMDI level.

4. However, the formaldehyde emission of plywood panels bonded with the hybrid adhesives increased at dry state, indicating incomplete curing of hybrid adhesives.

\section{ACKNOWLEDGMENT}

The authors are grateful for the financial support from the National Institute of Forest Science, Seoul, Republic of Korea.

\section{REFERENCES}

Cai, X., Riedl, B., Wan, H., Zhang, S.Y., Wang, X. 2010. A study on the curing and viscoelastic characteristics 
of melamine-urea-formaldehyde resin in the presence of aluminium silicate nanoclays. Composites Part A 41(5): 604-611.

Delebecq, E., Pascault, J.P., Boutevin, B., Ganachaud, F. 2012. On the versatility of urethane/urea bonds: Reversibility, blocked isocyanate, and non-isocyanate polyurethane. Chemical Reviews 113(1): 80-118.

Despres, A., Pizzi, A., Delmotte, L. 2006. ${ }^{13} \mathrm{C}$ NMR investigation of the reaction in water of UF resins with blocked emulsifiable isocyanates. Journal of Applied Polymer Science 99(2): 589-596.

Dunky, M. 1998. Urea-formaldehyde (UF) adhesive resins for wood. International Journal of Adhesion and Adhesives 18(2): 95-107.

Dunky, M. 2004. Adhesives based on formaldehyde condensation resins. Macromolecular Symposia 217(1): 417-430.

Frihart, C. R., 2005. Wood adhesion and adhesives: In Handbook of Wood Chemistry and Wood Composites, Ed. Roger M. Rowell. CRC Press, New York. 216-272.

Gopal G., Nath, S.K., Sujatha, D. 2014. Blocking of PMDI Resin and Mixed Phenol Blocked PMDI/Phenol Cardanol Formaldehyde Hybrid Resin for Plywood. International Journal of Applied Science-Research and Review 1(3): 117-128.

Hong, M.K., Park, B.D. 2017. Effect of UreaFormaldehyde Resin Adhesive Viscosity on Plywood Adhesion, Journal of Korean Wood Science and Technology 45(2): 223-231

Jeong, B., Park, B.D. 2016. Measurement of Molecular Weights of Melamine-Urea-Formaldehyde Resins and Their Influences to Properties of Medium Density Fiberboards, Journal of Korean Wood Science and Technology 44(6): 913-922.

Jiang, J., Lu, X. 2017. Improving characteristics of melamine-urea-formaldehyde resin by addition of blocked polyurethane prepolymer. European Journal of Wood and Wood Products 75(2): 185-191.
Kamoun, C., Pizzi, A., Zanetti, M. 2003. Upgrading melamine-urea-formaldehyde polycondensation resins with buffering additives. I. The effect of hexamine sulfate and its limits. Journal of Applied Polymer Science 90(1): 203-214.

Kandelbauer, A., Despres, A., Pizzi, A., Taudes, I. 2007. Testing by fourier transform infrared species variation during melamine-urea-formaldehyde resin preparation. Journal of Applied Polymer Science 106(4): 21922197.

Kim, S., Kim, H.J. 2005. Comparison of formaldehyde emission from building finishing materials at various temperatures in under heating system; ONDOL. Indoor Air 15(5): 317-325.

Kim, S. 2009. Environment-friendly adhesives for surface bonding of wood-based flooring using natural tannin to reduce formaldehyde and TVOC emission. Bioresourse Technology 100(2): 744-748.

Kissinger, H.E. 1957. Reaction Kinetics in Differential Thermal Analysis. Analytical Chemistry 29(11): 1702-1706.

KS. 2016. KS F3101: Plywood. Korean Standard Association, Seoul, Republic of Korea.

Li, X., Luo, J., Li, J., Gao, Q. 2016. Effects of diatomite inorganic fillers on the properties of a melamineurea-formaldehyde resin. Journal of Applied Polymer Science 133: 1-8.

Lubis, M.A.R., Park, B.D., Lee, S.M. 2017. Modification of urea-formaldehyde resin adhesives with blocked isocyanates using sodium bisulfite. International Journal of Adhesion and Adhesives 73: 118-124.

Lubis, M.A.R., Park, B.D. 2018. Analysis of the hydrolysates from cured and uncured ureaformaldehyde (UF) resins with two F/U mole ratios. Holzforschung 72: 759-768.

Mamiński, M.L., Pawlicki, J., Zado, A., Parzuchowski, P. 2007. Glutaraldehyde-modified MUF adhesive system - Improved hot water resistance. Holz als Roh-und Werkstoff 65(3): 251-253. 
Mansouri, H. R., Pizzi, A., Leban, J.M. 2006. Improved water resistance of UF adhesives for plywood by small pMDI additions. Holz als Roh-und Werkstoff 64(3): 218-220.

Merline, D.J., Vukusic, S., Abdala, A.A. 2013. Melamine formaldehyde: Curing studies and reaction mechanism. Polymer Journal 45(4): 413-419.

Park, B.D., Lee, S.M., Roh, J.K. 2009. Effects of formaldehyde/urea mole ratio and melamine content on the hydrolytic stability of cured urea-melamineformaldehyde resin. European Journal of Wood and Wood Products 67: 121-123.

Park, B.D., Kang, E.C., Lee, S.M., Park, J.Y. 2016. Formaldehyde emission of wood-based composite panels with different surface lamination materials using desiccator method, Journal of Korean Wood Science and Technology 44(4): 600-606.

Park, J.Y. 1998, Manufacturing of high water-resistant particleboard by combining use of urea resin and EMDI resin Journal of Korean Wood Science and Technology 26(1): 97-105.

Pizzi, A., 2003. Melamine-formaldehyde adhesives. Handbook of Adhesive Technology. Second edition. Marcel Dekker, New York, 653-679.

Siimer, K., Christjanson, P., Kaljuvee, T., Pehk, T., Lasn, I., Saks, I. 2008. TG-DTA study of melamine-urea- formaldehyde resins. Journal of Thermal Analysis and Calorimetry 92(1): 19-27.

Simon, C., George, B., Pizzi, A. 2002. UF/pMDI wood adhesives: Networks blend versus copolymerization. Holzforschung 56(3): 327-334.

Stöckel, F., Konnerth, J., Kantner, W., Moser, J., Gindl, W. 2010. Tensile shear strength of UF-and MUFbonded veneer related to data of adhesives and cell walls measured by nanoindentation. Holzforschung 64(3): 337-342.

Tohmura, S. I., Inoue, A., Sahari, S. H. 2001. Influence of the melamine content in melamine-ureaformaldehyde resins on formaldehyde emission and cured resin structure. Journal of Wood Science 47(6): 451-457.

Wicks, D. A., Wicks Jr, Z. W. 1999. Blocked isocyanates III: Part A. Mechanisms and chemistry. Progress in Organic Coatings 36(3): 148-172.

Wicks, D. A., \& Wicks Jr, Z. W. 2001. Blocked isocyanates III: Part B: Uses and applications of blocked isocyanates. Progress in Organic Coatings 41(1-3): 1-83.

Zhou, X., Pizzi, A., Du, G. 2012. The effect of nanoclay on melamine-urea-formaldehyde wood adhesives. Journal of Adhesion Science and Technology 26: 1341-1348. 